\title{
Analysis of growing season carbon and water fluxes of a subalpine wetland in the Canadian Rocky Mountains: implications of shade on ecosystem water use efficiency
}

\author{
Dylan Hrach $^{1}$, Richard Petrone ${ }^{1}$, Adam Green ${ }^{2}$, and Myroslava Khomik ${ }^{1}$ \\ ${ }^{1}$ University of Waterloo \\ ${ }^{2}$ University of Waterloo Faculty of Environment
}

March 30, 2021

\begin{abstract}
Mountain regions are an important regulator in the global water cycle through their disproportionate water contribution. Often referred to as the "Water Towers of the World", mountains contribute 40 to $60 \%$ of the world's annual surface flow. Shade is a common feature in mountains, where complex terrain cycles land surfaces in and out of shadows over daily and seasonal scales. This study investigated turbulent water and carbon dioxide fluxes over the snow-free period in a subalpine wetland in the Canadian Rocky Mountains, from June 7th to September 10th, 2018. Shading had a significant and substantial effect on water and carbon fluxes at our site. Each hourly increase of shade per day reduced evapotranspiration (ET) and gross primary production (GPP) by $0.42 \mathrm{~mm}$ and $0.77 \mathrm{gCm}-2$, equivalent to $17 \%$ and $15 \%$ per day, respectively, over the entire study period. However, during only peak growing season, when leaves were fully out and mature, shade caused by the local complex terrain, reduced ET and increased GPP, likely due to enhanced diffuse radiation. The overall result was increased water use efficiency at the site during periods of increased shading during the peak growing season. In addition to incoming solar radiation (Rg), temporal variability in ET was found to relate to temporal variability in soil temperature, moisture and vapour pressure deficit. Shade impacted the curvature and intercept of the nonlinear ET-Rg relationship at our site. In contrast, temporal variability in GPP at our site was dependent largely on Rg only. Our findings suggest that shaded subalpine wetlands can store large volumes of water for late season runoff and are productive through short growing seasons.
\end{abstract}

Analysis of growing season carbon and water fluxes of a subalpine wetland in the Canadian Rocky Mountains: implications of shade on ecosystem water use efficiency

D.M. Hrach, R.M. Petrone* , A. Green, M. Khomik

Hydrometeorology Research Group, Department of Geography and Environmental Management, University of Waterloo, 200 University Ave West, Waterloo, ON, Canada, N2L 3G1.

Corresponding Author: rpetrone@uwaterloo.ca

Disclosure Statement:

No potential conflict of interest was reported by the authors.

\section{Abstract}

Mountain regions are an important regulator in the global water cycle through their disproportionate water contribution. Often referred to as the "Water Towers of the World", mountains contribute 40 to $60 \%$ of the world's annual surface flow. Shade is a common feature in mountains, where complex terrain cycles land surfaces in and out of shadows over daily and seasonal scales. This study investigated turbulent water and 
carbon dioxide fluxes over the snow-free period in a subalpine wetland in the Canadian Rocky Mountains, from June $7^{\text {th }}$ to September $10^{\text {th }}, 2018$. Shading had a significant and substantial effect on water and carbon fluxes at our site. Each hourly increase of shade per day reduced evapotranspiration (ET) and gross primary production (GPP) by $0.42 \mathrm{~mm}$ and $0.77 \mathrm{gCm}^{-2}$, equivalent to $17 \%$ and $15 \%$ per day, respectively, over the entire study period. However, during only peak growing season, when leaves were fully out and mature, shade caused by the local complex terrain, reduced ET and increased GPP, likely due to enhanced diffuse radiation. The overall result was increased water use efficiency at the site during periods of increased shading during the peak growing season. In addition to incoming solar radiation $(\mathrm{Rg})$, temporal variability in ET was found to relate to temporal variability in soil temperature, moisture and vapour pressure deficit. Shade impacted the curvature and intercept of the nonlinear ET-Rg relationship at our site. In contrast, temporal variability in GPP at our site was dependent largely on Rg only. Our findings suggest that shaded subalpine wetlands can store large volumes of water for late season runoff and are productive through short growing seasons.

Keywords: shading, complex terrain, wetlands, evapotranspiration, carbon dioxide fluxes, gross primary production, water use efficiency, Canadian Rocky Mountains

\section{Introduction}

Subalpine wetlands provide a large range of ecosystem services within mountains and nearby lowlands, making water and carbon cycling within these systems important to understand. Although mountain terrain covers only $20 \%$ of the Earth's land mass, they contribute 40 to $60 \%$ of annual surface flow, making them an important regulator of the global water cycle (Ives \& Messerli, 1999; Grusson et al. 2015). As a result, many of the world's major rivers begin in alpine headwaters, where runoff from snowmelt may entirely comprise downstream flow (Viviroli et al. 2011). In areas that receive low summer precipitation, such as the semi-arid Western United States and Canada, alpine headwaters provide a natural and continuous water source for irrigation and municipal water supplies to over 60 million people (Barnett, Adam, \& Lettenmaier, 2005; Bales et al. 2006). Because of their large hydrological contributions, literature often refers to mountains as the "Water Towers of the World" (European Environment Agency, 2009; Immerzeel, 2008). The Canadian Rocky Mountains represent Western Canada's Water Tower, since they store and distribute large quantities of water resources to 13 million people across the western Canadian Prairie Provinces and American northcentral states (Fang et al. 2013).

Alpine wetlands, typically found within intermountain basins and upper mountain valleys (Windell et al. 1986), provide many important hydrological and ecological functions, such as flood mitigation, water for consumption and irrigation, support for important ecological habitats and carbon storage (Aber, Pavri, \& Aber, 2012). An important component of the alpine hydrological cycle is evapotranspiration (ET). Although in general, alpine ET has been extensively researched, ET and other physical processes within alpine wetlands remain poorly characterized (Souch, Wolfe, \& Grimmond, 1996). Wetlands are also an important contributor to carbon (C) storage, storing 12 to $15 \%$ of the global C pool (Cao et al. 2017), of which alpine wetlands contribute $2.5 \%$ (Zhao et al. 2010). Regionally the contribution of alpine ecosystems to local C-storage can be even greater. For example, in the Western United States alone, $70 \%$ of the carbon sink is located above 750 m.a.s.l, in landscapes that are $85 \%$ hills and/or mountains (Schimel et al. 2002; Desai et al. 2011). Distribution of carbon within alpine regions is extremely diverse. Hotspots of high soil organic carbon (SOG) have been found in moist to wet meadows, moderate SOG in dry meadows, and low SOG in fellfield (i.e. alpine tundra) (Knowles, Burns, Blanken, \& Monson, 2015). Yet, relatively few studies have observed carbon cycling in alpine wetlands, making them some of the least understood wetlands in the world (Wickland, Striegl, Mast, \& Clow, 2001; Cao et al. 2017). Although models indicate that globally wetlands may shift from sink to source of $\mathrm{C}$ under future climates, minimal research has been done on carbon source/sink dynamics in alpine wetlands and in understanding their controlling variables (Cao et al. 2017).

Ecosystem water use efficiency (WUE) is a useful metric to analyse the interaction of water and C fluxes of an ecosystem, as it is a proxy that quantifies photosynthetic carbon-uptake (GPP) per gram of water lost either through transpiration (T) or evapotranspiration (ET) (Rosenberg, Blad, \& Verma, 1983), depending 
on the scale and WUE-definition used. WUE has been measured on numerous scales, including: ecosystem, plant, and leaf level and is often used in agricultural and crop sciences (Medrano et al. 2015). WUE has been used in studies on mountain wetlands to help evaluate seasonal water resources (Hu et al. 2008; Han, Luo, Li, Ye, Chen, 2013; Strobl et al. 2017; Quan et al. 2018). Research has shown that WUE decreases with increased water availability, often resulting in lower WUE at high elevations in the subalpine zone (Han et al. 2013).

Strobl et al. (2017) also showed that ecosystem WUE adapts to environmental conditions, like microclimate and available energy, over the course of a day, making it a useful metric to help evaluate the influence of microclimates on $\mathrm{C}$ and water fluxes in mountain environments. Shade is a common feature in alpine basins, where complex terrain causes parts of the landscape to pass in and out of shadows over daily and seasonal time scales ( Marsh, Pomeroy, \& Spiteri, 2012) . Shade can significantly reduce the available energy in mountain ecosystems during the snow-free period and create distinct microclimates compared to non-shaded areas (Hrach, Van Huizen, Khomik, \& Petrone, 2021). However, little research has been conducted on the impact of shade on water and carbon cycling within mountain landscapes, especially wetlands.

The main objectives of this research were to: 1) characterize growing season carbon and water dynamics of an alpine wetland located in complex terrain; 2) explore if and how horizon shade (Essery \& Marks, 2007; Marsh et al. 2012), caused by the local complex terrain, influences water use efficiency of the wetland; and 3) investigate which key environmental factors, including shade, could explain the temporal variability in observed carbon and water fluxes. Note, in this study we define WUE as the ratio between GPP and ET. Given that water fluxes are related to available energy through latent heat of vaporization, we hypothesized that ET will be negatively affected by horizon shade and cause an increase in or unchanged WUE, if C-fluxes are unaffected or if C-fluxes also decrease with shade, respectively.

\section{Study Site}

The study was conducted at Fortress Mountain $\left(50.82^{\circ} \mathrm{N}, 115.21^{\circ} \mathrm{W}\right)$ - a non-active alpine ski resort, located $80 \mathrm{~km}$ West of Calgary, Alberta, in the Kananaskis Range of the Canadian Rocky Mountains (Figure 1A, B). The study site, called Bonsai, was a marsh meadow, about 1 ha in size with a topographic boundary outlined by: a headwall ( $\sim 500 \mathrm{~m}$ high) to the south, an ephemeral tarn to the North, and ridges ( $\sim 150 \mathrm{~m}$ high) to the East and West (Figure 1C). The site was mostly-flat with a moderate increasing slope of 6 degrees (2083 to 2086 m.a.s.l.) from the tarn to the base of the talus slopes (50 m distance). Because of the headwall to the South and ridge to the East, different portions of the wetland were shaded for long durations of time across the day and season, which promoted a deep snowpack, long snow-covered period, extended spring melt period, and a constrained growing season.

The soil at the site was comprised of a thin layer of pervious well-sorted sand above a semi-pervious layer of very fine silt across much of the wetland, with increased gravel near the headwall. Vegetation was comprised of shade tolerant wetland species, including:Equisetum, Salix , Castilleja raupii, andErigeron caespitosus . The hydrology of the site consisted of a deep water-table $(>2 \mathrm{~m})$ and two surface streams, one on the East and one on the West margin of the wetland. These streams met at a confluence in the North-Central section of the wetland, where they drained into the tarn, which then drained into Galatea Creek and downslope to the Kananaskis River (a tributary to the Bow River - a major river in the area and a tributary of the South Saskatchewan River). For more information about the site characteristics please refer to Hrach et al. (2021).

\section{Materials and Methods}

\section{Meteorological Data}

A meteorological tower was installed at the site in the centre of the wetland and instrumented with meteorological equipment to monitor environmental conditions from 7 June to 10 September 2018. Measurements were taken every 10 seconds and averaged half-hourly on a 9210XLite data Logger (Sutron, Stirling, Virginia, USA). Wind speed was measured by an R.M. Young $05103-10 \mathrm{~A}$ anemometer (Traverse City, Michigan, USA) at a height of $3.8 \mathrm{~m}$. Net radiation was measured with a net radiometer (NR Lite, Kipp and Zonen, 
Delft, Netherlands) and photosynthetically active radiation was measured by a quantum sensor (Li-Cor 2319, LI-COR, inc., Lincoln, Nebraska, USA) at $3.1 \mathrm{~m}$. Air temperature $\left(\mathrm{T}_{\mathrm{a}}\right)$ and relative humidity $(\mathrm{RH})$ were measured with an HMP-155 probe at 3.4m (Vaisala, Helsinki, Finland). Two soil heat flux plates (HukseFlux Thermal Sensor HFP01, Delft, Netherlands) were placed under the soil surface at $5 \mathrm{~cm}$ depths to measure average ground heat flux. Two ECH2O EC-5 sensors (Meter Group, Hopkins, Washington, USA) measured the average soil moisture at a $10 \mathrm{~cm}$ depth in a soil pit adjacent to the tower, and soil temperatures $\left(\mathrm{T}_{\mathrm{S}}\right)$ was measured at 3 depths in the soil pit $(2,5, \& 10 \mathrm{~cm})$ with Li-Cor $7900-180$ soil temperature probes (LICOR Inc., Lincoln, Nebraska, USA). Rainfall was measured by a tipping bucket rain gauge (Onset Computer Corp, Massachusetts, USA) in a forested clearing $350 \mathrm{~m}$ North of the study site, at a similar elevation as the wetland. A Moultrie Wingscapes time lapse camera captured images in three-hour intervals everyday from 6 am to 9 pm from May $25^{\text {th }}$ to September $7^{\text {th }}, 2018 \backslash$ sout.

Eddy Covariance Measurements

Water $\left(\mathrm{H}_{2} \mathrm{O}\right)$, carbon dioxide $\left(\mathrm{CO}_{2}\right)$ and momentum fluxes were measured at the site with an Eddy Covariance (EC) system deployed at the meteorological tower from 7 June to 10 September. The EC system consisted of a 3D sonic anemometer (CSAT3; Campbell Scientific Inc., Logan, Utah, USA) and an open-path infrared $\mathrm{CO}_{2} / \mathrm{H}_{2} \mathrm{O}$ gas analyzer (IRGA) (LI-7500, LI-COR Inc., Lincoln, Nebraska, USA) mounted $3 \mathrm{~m}$ above the surface. Raw fluxes were sampled at a frequency of $10 \mathrm{~Hz}$ on a CR1000 datalogger (Campbell Scientific, Logan, Utah, USA) and averaged over a half-hour. All fluxes were corrected for density, sensor separation, time lag and coordinate rotation (double coordinate rotation was used) following common Fluxnet protocols (Webb, Pearman, \& Leuning, 1980; Kaimal and Finnigan, 1994; Leuning and Judd, 1996; Foken and Leclerc, 2004; Aubinet et al., 2012; Burba et al., 2012). The resulting half-hour fluxes were then processed in a custom R-Software script, which filtered each half-hour to ensure that it had at least $80 \%$ of the high-frequency records and that there was no potential for dew formation on the IRGA lenses by either precipitation or by comparing the dew point temperature to $T_{a}$. Additional filtering removed values that were greater than \pm 3 standard deviations of a moving average, which consisted of 10 half-hour neighbouring values; further filtering was completed to check for physically improbable values. The Kljun, Calanca, Rotach, \& Schmid (2015) footprint analysis was used to constrain the measured fluxes to be within $80 \%$ of the desired site boundaries, using their FFP R-functions. Thereafter, fluxes with a corresponding friction velocity $\left(\mathrm{u}^{*}\right)$ of $\mathrm{u}^{*}$ $<0.15 \mathrm{~ms}^{-1}$ were removed from the dataset. Following this, the filtered net ecosystem exchange (NEE) data was gap-filled using the MDS method outlined in Reichstein et al. (2005); and then partitioned into respiration (R) and gross primary productivity (GPP) using the relationship between night-time respiration and $\mathrm{T}_{\mathrm{a}}$ (Reichstein et al., 2005). The filtered energy fluxes were forced closed, with the additional energy partitioned based on the Bowen ratio ( $\beta)$ (Wilson et al., 2002). $\beta$ is the ratio of sensible heat $\left(\mathrm{Q}_{\mathrm{h}}\right)$ to latent heat $\left(\mathrm{Q}_{\mathrm{e}}\right)$. For each available half-hour, $\mathrm{Q}_{\mathrm{e}}$ was gap-filled by scaling potential evapotranspiration, PET (Priestley and Taylor, 1972) to ET. The scaler $(\alpha)$ was calculated from the ratio between ET and PET. For periods where no $\alpha$ was available, the ratio was gap-filled using the MDS method outlined in Reichstein et al. (2005), where $\mathrm{Q}^{*}, \mathrm{VPD}$, and $\mathrm{u}^{*}$ were used as the gap-filling conditions; however, when this was not possible, the seasonal mean $\alpha$ was used. $Q_{h}$ was then gap-filled by solving the energy balance equation using the measured and gap-filled $\mathrm{Q}^{*}, \mathrm{Q}_{\mathrm{e}}$ and $\mathrm{Q}_{\mathrm{g}}$.

Statistical Analysis

Data was analyzed using four key seasonal phases during our study period, defined by snowpack thickness and vegetation phenology:Snow Melt (7 to 23 June; day of year (DoY) 158 to DoY 174);Green-Up (24 June to 20 July; DoY 175 to DoY 201); Peak Growing Season (21 July to 23 August; DoY 202 to DoY 235); andLate Growing Season (24 August to 10 September; DoY 236 to DoY 253). More details on how the "seasonal phases" were chosen and defined can be found in Hrach et al. (2021). Furthermore, the study period data was divided based on Stable Shade with consistent average daily shade of around 2 hours (7 June to 30 July) andDynamic Shade with increasing average daily shade (31 July to 10 September). Horizon shade results from Hrach et al. (2021) were used in a linear regression model to understand the general influence of shade (independent variable) on the water and carbon fluxes (dependent variables) during the 
course of the entire study period.

In order to better understand the effect of shade and other environmental controls on explaining the temporal variability in ET, GPP, and WUE at our site, attention was focused on the Peak Growing Season. This avoided the confounding effects of changing phenology (i.e. increasing leaf area during Green up or senescence during Late Growing Season ). It was assumed that maximum leaf area occurred during Peak Growing Season , which was confirmed by GPP data as the time of peak productivity. This was also the only season which had both Dynamic shade andSteady shade days during our study. Since we were also interested in WUE differences between Dynamic and Steady shade, the dataset was further filtered to have only daytime values $(\mathrm{Rg}>50 \mu \mathrm{mol} / \mathrm{mol})$, since during the night $\mathrm{GPP}=0$ and WUE should be zero by definition. Finally, only observed data was used in this analysis, such that there were no gap-filled observations.

With the filtered data set ( $\mathrm{n}=247$, with 167 data points fromDynamic shade period and 80 from Steady shade days), general additive modelling (GAM) was used to investigate which of the following environmental variables best described the temporal variability in ET and GPP: incoming photosynthetically active radiation (used as a surrogate for incoming shortwave radiation, $\mathrm{Rg}$ ), soil moisture - an average of 2-10cm depths (SM), soil temperature at $2 \mathrm{~cm}$ depth (Tsoil.2cm), vapour pressure deficit(VPD), and shade as a factor (fShade, which was 0 for Steady shade data and 1 for Dynamic shade data). Day of year (DoY) and time of day (Hour) were also used as explanatory variables to account for any temporal variability. Adding time into the autocorrelation structure did not improve the quality of model as much as adding time directly as an input variable. Additional variables, such as air temperature, relative humidity, soil temperature at other depths $(5$ and $10 \mathrm{~cm}$, as well as a mean of $2-10 \mathrm{~cm}$ ), net radiation and ground heat flux, were also considered at the beginning, but all of these variables were highly correlated with the final chosen set, so they were not included in the model selection runs. Only variables that had the highest correlations with the response variables (i.e. ET and GPP) were tested in the models. The "mgcv" R-package (Wood, 2004, 2011, 2017) was used for this analysis. Model selection was based on Akaike's Information Criterion (AIC), where the model with the largest change in AIC ( $\triangle$ AIC) was deemed best fitting. Models with delta-AIC less than 2 were deemed similar. Once the best fitted model was determined, we reran the model, excluding one of the key explanatory variables at a time and plotted the observed vs predicted values. The adjusted $\mathrm{R}^{2}$ of the 1:1 relationship between the observed and predicted values from such models was used to assess the relative contribution of each of the explanatory variables in the final best-fitted model to explaining the temporal variability in the response variable modelled.

All other statistical analyses were performed and summarized with packages dplyr , reshape2 (Wickham, 2007), tidyr (Wickham \& Henry, 2019), and illustrated with ggplot2 in RStudio. Prior to any analysis, data was assessed for normality through a Shapiro-Wilks normality test, which concluded that all daily data used in this analysis was normaly distributed $(\mathrm{p}>0.05)$, other than the hill shade model output. Since the hill shade results are the independent variable and the remainder of the data was accepted by the Shapiro-Wilks test, parametric testing was acceptable to use in the statistical analysis.

\section{Results}

Site Climatic Conditions during the Study Period

Average air temperature at the wetland over the study period was $9{ }^{\circ} \mathrm{C}( \pm 4.1)$, with a daily maximum of $18.6{ }^{\circ} \mathrm{C}$ on 10 August and a daily minimum of $0.8{ }^{\circ} \mathrm{C}$ on 11 June (Figure $2 \mathrm{~b}$ ). The soil surface remained frozen until 20 June and then rapidly increased in temperature from $-0.3^{\circ} \mathrm{C}$ to $7.4{ }^{\circ} \mathrm{C}$ over a three-day period (Figure 2b). The spring thaw aligned with the appearance of snow-free areas around the tower. Snowfall was captured on the site's time-lapse camera as late as 2 July and began again on 29 August. Precipitation was frequent and intense at the beginning of the study period, when two individual days received upwards of 33 mm (Figure 2c). Overall, rainfall from June to August reached $339 \mathrm{~mm}$ at Bonsai (Figure 2c), similar to the historic seasonal average across Marmot Creek Research Basin (342mm), located $14 \mathrm{~km}$ North of the study site in the Kananaskis Range (DeBeer \& Pomeroy, 2009).

During the 2018 study period at Bonsai, air temperature and precipitation values were similar to the 30-year 
(1981 - 2010) normals reported by an Environment and Climate Change Canada (ECCC) monitoring station (ID 3053600: $51.03 \mathrm{~N}, 115.03 \mathrm{~W}, 1,391 \mathrm{~m}$.a.s.l.), located $28 \mathrm{~km}$ North of the study site. Average monthly air temperatures at the ECCC station in 2018 were within 2 standard deviations (except for September) of the respective monthly ECCC normals with $11.4{ }^{\circ} \mathrm{C}( \pm 1.1), 14.5{ }^{\circ} \mathrm{C}( \pm 1.5), 13.8{ }^{\circ} \mathrm{C}( \pm 1.5)$, and $9.4{ }^{\circ} \mathrm{C}( \pm 1.9)$ in June, July, August, and September, respectively. The 30-year average annual precipitation at the ECCC station was $639.3 \mathrm{~mm}$, with $119.4 \mathrm{~mm}, 64.9 \mathrm{~mm}, 70.8 \mathrm{~mm}$, and $72.8 \mathrm{~mm}$ falling over the months of June, July, August, and September, respectively.

When environmental variables were analyzed for differences between the two shade periods during Peak Growing Season, it was clear that the amount of incoming radiation was substantially lower duringDynamic shade compared to Steady shade (Figure 2a). Both incoming radiation and net radiation were reduced by about 25\%. The period of Dynamic shade during Peak Growing season had warmer (by about 11\%) air temperatures compared to Steady shade, but this did not result in much change in soil temperatures (Figure 2).Dynamic shade had lower soil moisture and higher vapour pressure deficit, suggesting there was somewhat less moisture in the system at the time.

Growing Season Water and Carbon Dynamics of a Subalpine Wetland with Complex Terrain

Across the entire 2018 study period (96 days), cumulative evapotranspiration (ET) reached a total of 157.7 $\mathrm{mm}$. During Snow Melt (17 days in duration), mean ET was $1.0 \mathrm{~mm}$ /day $( \pm 0.7)$ and increased throughout the seasonal phase (Figure 3), because of evaporation from snowmelt runoff. During this season ET was most likely dominated by evaporation, since the majority of the wetland vegetation was still under a blanket of snow and without leaves. Cummulative ET during snowmelt was $16.6 \mathrm{~mm}$. ET continued to increase into Green $U p$, reaching the seasonal maximum for the entire study period (3.5mm/day) from 12 - 17 July (DoY 193-198). Overall, Green Up had a daily average ET of $2.3 \mathrm{~mm} /$ day $( \pm 1.1)$, contributing $57.5 \mathrm{~mm}$ to the overal cumulative ET. Green Up represented only $28 \%$ of the study period (27 days), but made up $37 \%$ of total study period ET.Throughout Snowmelt and Green Up the site experiencedSteady shade (around 2 hours of shade daily). After Green $U p$, ET was influenced by the increasing horizon shadow effect and followed a decreasing trend, similar to Rg through the remainder ofPeak Growing Season and into Late Growing Season (Figure 2a and Figure 3). Therefore, daily Peak Growing Season ET was lower than Green $U p$ with a daily average of $2.0 \mathrm{~mm} /$ day $( \pm 0.5)$. Since Peak Growing season was longer $(35 \%$ of study period, 34 days), it resulted in a greater cumulative total ET $(66.6 \mathrm{~mm})$ compared to Green Up despite the lower daily mean ET. Peak Growing Season contributed $42 \%$ of total study period ET. During Late Growing Season, ET remained low (mean of $0.94 \mathrm{~mm} /$ day $( \pm 0.3)$ ) and contributed only $11 \%(17.0 \mathrm{~mm})$ to total study period ET. Therefore,Green Up and Peak Growing Season accounted for the largest (124.1 mm, 79\%) chunk of cumulative ET during the course of this study.

In this study we use the term "carbon flux" to represent only carbon dioxide $\left(\mathrm{CO}_{2}\right)$ exchange between the wetland and the atmosphere. The carbon (C) flux was extremely variable during Snow Melt and represented a strong source, defined as negative Net Ecosystem Exchange $\left(\mathrm{NEE}=\mathrm{GPP}-\mathrm{R}_{\text {eco }}\right.$ ), releasing an average of $1.4 \mathrm{gCm}^{-2}$ day $( \pm 2.2)$ into the atmosphere for a total release of $23.8 \mathrm{gC}$ over this period (Figure 4). During Snow Melt, there was no photosynthetically active vegetation present so almost all NEE was defined by Ecosystem Respiration $\left(\mathrm{R}_{\text {eco }}\right)$. The wetland then fluctuated between a source and sink during Green Up, when variability in $\mathrm{CO}_{2}$ uptake/release continued until the $6^{\text {th }}$ of July. During this time the ground surface became increasingly snow-free and vegetation began leafing-out. Following the $6^{\text {th }}$ of July, the wetland was a net C-sink (i.e. $\mathrm{CO}_{2}$ uptake with positive NEE) until theLate Growing Season . During the Green Up season, the wetland took up an average of $0.58 \mathrm{gCm}^{-2}$ day $( \pm 0.7)$ for a total carbon sink of $15.6 \mathrm{gC}$. Maximum $\mathrm{CO}_{2}$ uptake from photosynthesis (defined as Gross Primary Production: GPP) occurred from 29 July to 2 August, once the entire site became snow-free and vegetation began to grow, with an average daily GPP of $6.4 \mathrm{gCm}^{-2}$ day and $\mathrm{R}_{\text {eco }}$ of $4.5 \mathrm{gCm}^{-2}$ day, respectively. This equated to an average NEE of $1.9 \mathrm{gCm}^{-2}$ day $( \pm 0.5)$, representing a net carbon sink of $60.5 \mathrm{gC}$ over the Peak Growing Season. Net C sequestration largely took place between the hours of 08:00 and 19:00 duringPeak Growing Season from the middle of July to the end of August (Figure 7). At this time, cumulative net $\mathrm{CO}_{2}$ uptake was high enough to offset $\mathrm{CO}_{2}$ losses 
during the Snow Melt period and shift the wetland into a cumulative net sink (Figure 4b). Following the seasonal maximum, there was a decreasing trend in the net $\mathrm{C}$ flux for the remainder of the study. During the Late Growing Season period, the site remained a consistent C sink with a net C uptake of $0.6 \mathrm{gCm}^{-2}$ day $( \pm 1.0)$ for a cumulative sink of $10.6 \mathrm{gC}$. NEE spiked to $3.3 \mathrm{gC}$ on 7 September because of abnormally warm air temperature $\left(9.4^{\circ} \mathrm{C}\right)$ compared to the Late Growing Season's average of $5.5^{\circ} \mathrm{C}$. Over the entire study period, Bonsai was a net sink of $63 \mathrm{gC}$; however, it is possible that the wetland is an overall annual source of $\mathrm{CO}_{2}$ if emissions during the snow-covered period are similar to what we found during Snow Melt .

Environmental Factors driving Temporal Variability in Observed Carbon and Water Fluxes

Bonsai carbon flux was influenced by shade and had a statistically significant negative relationship with GPP $\left(\mathrm{R}^{2}=0.75 ; \mathrm{p}<0.01\right)$ and $\mathrm{R}_{\text {eco }}\left(\mathrm{R}^{2}=0.39, \mathrm{p}<0.05\right)$, and a statistically significant positive relationship with NEE $\left(\mathrm{R}^{2}=0.73, \mathrm{p}<0.01\right)$ during Dynamic Shade (Figure $\left.5 \mathrm{~b}\right)$. This indicates that each hourly increase of shade during Dynamic Shade decreased GPP by $0.8 \mathrm{gCm}^{-2}$ day $(\mathrm{y}=-0.8 \mathrm{x}+6.7)$, overall decreasing the $\mathrm{C}$ sink strength (NEE) by an average of $0.5 \mathrm{gCm}^{-2}$ day $(\mathrm{y}=-0.5 \mathrm{x}+3.9)$. Therefore, horizon shade negatively impacted $\mathrm{C}$ uptake at the site. The period ofStable Shade yielded non-significant results for $\mathrm{R}_{\text {eco }}$ (Figure 5a). Thus, other environmental variables influenced the temporal variability in water and carbon fluxes inStable Shade

ET also had a statistically significant negative relationship $\left(\mathrm{R}^{2}=0.66, \mathrm{p}<0.01\right)$ with hours of shade per day (hrs/day) during Dynamic Shade (Figure 5b), but not duringStable Shade $\left(\mathrm{R}^{2}=0.04, \mathrm{p}>0.05\right)$ (Figure 5a). During Dynamic Shade, each hour of shade decreased ET losses by $0.42 \mathrm{~mm} /$ day $(\mathrm{y}=-0.4 \mathrm{x}+3.3)$. Therefore, there was a statistically significant relationship between ET and available energy over the study period $\left(\mathrm{R}^{2}=0.79, \mathrm{p}<0.01\right)$, indicating that increased shade (and lower available energy) decreased evaporative losses and established a greater potential for water storage.

Figures 6 and 7 displayed similar results to the statistical analysis above, in which ET and GPP were strongly influenced by the horizon shadow. In a uniform and non-complex environment, fluxes typically display a bellcurve pattern, increasing in the morning, peaking in the afternoon, and gradually decreasing into the evening. However, at Bonsai there was a noticeable shift from this pattern in the middle of July, when half hourly ET had a sudden reduction at 16:00 hours (0.13 to 0.05mm, Figure 6). This trend became more intense into August and the period of Dynamic Shade, when shade decreased energy and water fluxes in the morning from 09:00 to 11:00 hours and at 15:00 hours in the afternoon (Figure 7). The response of ET to horizon shade followed a nearly identical pattern as that of Rg and $\mathrm{Q}^{*}$ (Figure 6). ET (and Rg) should have declined from the afternoon until sunset; however, sharp reductions were observed at 16:00 hours in the middle of July, indicating that horizon shade shaped the energy and water fluxes during the Peak Growing Season . Similar to the results found in the statistical analysis, GPP did not follow the same pattern as ET, Rg, or Q* during constant shade, but did have a narrowing bell curve shape in the portion of increasing shade in Peak Growing Season. High $\mathrm{R}_{\text {eco }}$ during the Snow Melt period resulted in a C source (averaging $1.4 \mathrm{gCm}^{-2}$ day $^{-1}$ ) with the largest $\mathrm{C}$-source contributions occurring from advection overnight, in the middle of June between 22:00 and 06:00 hours. C uptake through GPP was greatest midday from the middle of July to the middle of August between the hours of 08:00 and 18:00. In the middle of August there was a rapid decline in $\mathrm{C}$ uptake, as the wetland transitioned from $0.3 \mathrm{gC} / \mathrm{hh}$ to $0.06-0.13 \mathrm{gC} / \mathrm{hh}$ and closer to net neutral C uptake during daytime hours.

Using general additive modelling and the list of key environmental variables that were available to us from measurements at the site, we were able to explain up to $84 \%$ of temporal variability in ET (Table 4), but only $71 \%$ of GPP (Table 5). For both water and carbon fluxes, we found that the most significant variable in explaining the temporal variability was incoming solar radiation $(\mathrm{Rg})$. For GPP, $\mathrm{Rg}$ was the most important variable, reducing model performance the most, if excluded. Interestingly, the model for ET had more variables that were significant in explaining its temporal variability (Table 4), including surface soil temperature (at $2 \mathrm{~cm}$ depth), vapour pressure deficit, shade - as a factor variable, and time of day (Hour). In contrast, the model for GPP had day of the year (DoY) as the only other variable that turned out to have statistically significant estimated coefficients in the best-fitting model (Table 5). All other variables tested 
were not significant. This finding supported the spectrographs of the data (Figure 6), where the changes in ET seemed to be more visually correlated to changes in Rg than GPP. Our analysis suggests that ET was related to the temporal variability in environmental variables, while GPP was dependent on plant physiology (which was not measured in this study) such as leaf area and greenness factor. This is further evidenced by the fact that GPP continued to increase throughout the Peak Growing Season, despite decreased Rg, having a higher mean GPP value inDynamic Shade versus Stable Shade (Table 1). Although, the difference was not found to be statistically significant. Another interesting finding was that ET was nonlinearly related to Rg and that the two curves differed between Dynamic Shade versusSteady Shade (Table 4 and Appendix 2 ). The estimated parametric coefficient for shade-factor in the ET model was also negative for the Steady Shade group (Appendix 2: fShadeSteady=-0.0096116), which meant that the curve for Steady Shade was offset from Dynamic Shade (lower intercept), such that for a given Rg value, ET will be higher in Dynamic Shade thanSteady Shade. This was evident if we looked at our observed data using binned-Rg (Appendix 3). Dynamic Shade had a lower mean ET because shade reduced overall Rg, resulting in more values at lower Rg during that period (Appendix 3). Interestingly, this was not the case for GPP, where shade factor was not found to be significant in the best-specified gam model (Table 5 and Appendix 1). Here, GPP was higher with lower Rg-bins (Dynamic Shade), but not much different from higher Rg-bins (Steady Shade ) (Appendix 3). These finding have implications for the local water balance and support the notion that shaded ecosystems have reduced overall water loss from shade, because of greater reductions in evaporation than transpiration.

Seasonal Water Use Efficiency of a Subalpine Wetland and the impact of Horizon Shade

When considering the full data set, from Green Up to Late Growing Season, Bonsai had an average WUE of $2.9 \mathrm{gC}\left(\mathrm{kg} \mathrm{H}_{2} \mathrm{O}\right)^{-1}$ day $( \pm 0.80)$ and WUE was highest during periods of peak productivity (Peak Growing Season ) and lowest during shoulder seasons (Green Up \& Late Growing Season ) (Table 1). Maximum WUE (5.3 $\left.\mathrm{gC}\left(\mathrm{kg} \mathrm{H}_{2} \mathrm{O}\right)^{-1}\right)$ occurred on 20 August and minimum WUE $\left(1.4 \mathrm{gC}\left(\mathrm{kg} \mathrm{H}_{2} \mathrm{O}\right)^{-1}\right)$ occurred on 29 June. During the seasonal maximum, vegetation was highly productive, but had less water available, while during the seasonal minimum vegetation was not yet fully grown and productive despite having a large amount of available water. Periods surrounding the maximum and minimum illustrate the seasonal trends in WUE; during Green Upand Late Growing Season Bonsai had low daily averages $\left(2.4\right.$ and $2.9 \mathrm{gC}\left(\mathrm{kg} \mathrm{H}_{2} \mathrm{O}\right)^{-1}$, respectively), while in Peak Growing Season there were high daily averages $\left(3.35 \mathrm{gC}\left(\mathrm{kg} \mathrm{H}_{2} \mathrm{O}\right)^{-1}\right)$. Increased ET during Green Up led to a lower WUE and a greater GPP in Peak Growing Season resulted in a higher WUE.

To better understand the impact of shade on WUE at Bonsai, we focused our attention on the Peak Growing Season and daytime data only. We found that the mean GPP was higher for data from SteadyShade period compared to Dynamic Shade $\left(0.179 \mathrm{gC} / \mathrm{m}^{2} / \mathrm{hh}\right.$ vs $\left.0.173 \mathrm{gC} / \mathrm{m}^{2} / \mathrm{hh}\right)$; however, this difference was not statistically significant (Table 1). Mean ET on the other hand was lower during the DynamicShade period compared to Steady Shade $(0.070 \mathrm{~mm} / \mathrm{hh}$ vs $0.077 \mathrm{~mm} / \mathrm{hh})$. Again, this difference was also not statistically significant (Table 1). However, these differences in GPP and ET resulted in a statistically significant difference in the mean WUE values between the two shaded periods, with Dynamic Shade mean WUE being higher compared to that of Stable Shade (3.10 vs $2.72 \mathrm{gC} / \mathrm{mm}$, Table 1). Since both ET and GPP were most dependent on the temporal variability in $\mathrm{Rg}$ (and that $\mathrm{Rg}$ was reduced by shade), shade had an impact on WUE, increasing it via reductions in ET and potential increases in GPP. The binned data suggests improved photosynthetic rates for lower Rg-bins compared to higher Rg-bins during Dynamic shade (Appendix 3).

\section{Discussion}

Climate conditions within the Kananaskis Valley (1,391 m.a.s.l.) are indicative of continental air masses, with long cold winters and an average air temperature of $-15{ }^{\circ} \mathrm{C}$ from January to March . Average annual precipitation is $900 \mathrm{~mm}$ in the valley and subalpine region, but increases to well above $1140 \mathrm{~mm}$ in elevations greater than treeline. Snow cover remains from November to June, because of cold temperatures and large contributions of precipitation from snowfall (65-70\%) (DeBeer \& Pomeroy, 2009; Marsh et al. 2012). The melt period often begins in April, as temperatures increase, and finishes in July coinciding with maximum 
solar radiation and temperature . Climate at Bonsai during the study period was representative of the typical conditions experienced within the subalpine region of the Valley. The climate also varied at our site during periods of Dynamic andSteady shade.

Growing Season Evapotranspiration from a Subalpine Wetland

Our wetland had lower ET (157.7 mm) over the summer compared to other subalpine meadows and wetlands because of its shorter growing season and the impact of horizon shade (Table 3). Past studies reported that subalpine wet meadows (Groeneveld, Baugh, Sanderson, and Cooper, 2007; Wu et al. 2015) and wetlands (Sanderson \& Cooper, 2008) have a large range in annual ET that reach up to $994 \mathrm{~mm}$, with growing season (May to October) contributions of $200-657 \mathrm{~mm}$. Large seasonal differences in ET are often caused by localised environmental variables that alter season length, such as solar radiation, air temperature, precipitation, water table depth, and soil moisture content (Flerchinger, Marks, Reba, Yu, and Seyfred, 2010; Wu et al. 2015). In our study, low cumulative ET at the wetland was due to the strong relationship between ET, available energy, and horizon shade. Throughout the measurement period, shade supported a thick snowpack, delayed transpiration contributions to ET, and limited the available energy during critical daily and seasonal growth periods. The influence of shade was evident when our site was compared to studies conducted at other subalpine wetlands with similar climates, vegetation structure, soil moisture, and water table depth. A playas wetland (2,296 m.a.s.l.) in San Luis Valley (SLV), Colorado (Sanderson \& Cooper, 2008) had a higher annual ET range, from 352 to $571 \mathrm{~mm}$ (although, over a longer period, from April to October). The playas wetland in the SLV had similar environmental controls as our wetland, with mild summer temperatures and cold winters (July mean $=17{ }^{\circ} \mathrm{C}$, January mean $=-9{ }^{\circ} \mathrm{C}$ ), low summer precipitation $(128-189 \mathrm{~mm}$ ), fine-grained soils, a low water table $(>1 \mathrm{~m})$, and sparse vegetation dominated by sedge and grass; indicating that one of the limiting variables for low ET at our wetland was the growing influence of horizon shade in the growing season. This impact of horizon shade was visible when observing the hourly and daily patterns of water fluxes across the season at our site and was supported by our GAM-modelling analysis.

We found similar seasonal ET patterns to other subalpine wetlands, defined by an increase through Snow Melt , peak ET during Green Up, and a steady decline throughout Peak Growing Season into Late Growing Season (Cooper, Sanderson, Stannard, and Groeneveld, 2006; Sanderson \& Cooper 2008; Wang, Wang, Zheng, and Guo, 2012). ET was greatest during Green Up because of large inputs from snowmelt evaporation and transpiration from greening wetland vegetation, including trees and shrubs. Throughout Green Up,incoming solar $(\mathrm{Rg})$ and net radiation $\left(\mathrm{Q}^{*}\right)$ remained high following the solar maximum and provided large energy contributions to sustain latent $\left(\mathrm{Q}_{\mathrm{e}}\right)$ and sensible $\left(\mathrm{Q}_{\mathrm{h}}\right)$ heat fluxes, as was shown in Hrach et al. (2021). There were also noticeable spikes in ET during the midday hours (12:00 to 17:00) of early June (Figure 6), because of evaporation from snowmelt runoff. Following this, ET continued to increase until the seasonal maximum, which lasted from 12 - 17 July, two weeks before the max ET reported in other studies (Cooper et al. 2006; Wu et al. 2015). Maximum seasonal ET occurred earlier at our site because of the growing influence of shade as the season progressed.

We found that the seasonal water fluxes were strongly influenced by the relationship between available energy and horizon shade. Hrach et al. (2021) found that each hourly increase of shade during Dynamic Shade reduced daily $\mathrm{Rg}$ and $\mathrm{Q}^{*}$ by $13 \%$ and $16 \%$, respectively. Since ET was largely controlled by the available energy, we expected that shade would also strongly influence ET. During Dynamic Shade, each hourly interval of shade per day decreased ET by 17\%, similar to other studies, which found that lower ET aligned with periods of reduced available energy and higher shade. Shade was an important control mechanism on the water and energy fluxes at Bonsai over the summer months.

Variability in Subalpine Wetland Carbon Flux

The C flux varied greatly over the study period as the system quickly shifted between a C source and sink in response to changing environmental conditions following Snow Melt . Considering all seasonal phases, the study period was a cumulative net sink of $63 \mathrm{gCm}^{-2}$ and was comparable to snow-free period values reported in other mountain ecosystems, such as sub-alpine meadows (Kato et al. 2003), and wetlands (Zhao et al. 2010; 
Millar, Cooper, Dwire, Hubbard, and von Fischer, 2017) studies. Average growing season NEE in subalpine alpine wetlands varies from strong sinks at the Qinghai Tibet Plateau (46 to $212 \mathrm{gCm}^{-2}$ ) (Kato et al. 2003; Kato et al. 2006; Zhao et al. 2010), to strong sources and sinks (-342 to $256 \mathrm{gCm}^{-2}$ ) in the Rocky Mountains of Wyoming and Colorado (Knowles et al. 2015; Millar et al. 2017). Although alpine systems show varying results in ecosystem source/sink strength, winter C flux can cause alpine meadow and wetland ecosystems to be a strong $\mathrm{C}$ sources, due to the insulating properties of snow cover that keeps the ground surface unfrozen and soil respiration $\left(\mathrm{R}_{\mathrm{s}}\right)$ active (Zhao et al. 2010; Knowles et al. 2015; Lange, Allaire, Castillo, and Dutille, 2016). In our study, snowpack kept soil temperature $(2,5$, and $10 \mathrm{~cm})$ above $-5{ }^{\circ} \mathrm{C}$ during Snow Melt, meeting the threshold required for $\mathrm{R}_{\mathrm{s}}$ to occur (Brooks, Schmidt, and Williams, 1997). This indicated that $\mathrm{R}_{\text {eco }}$ was representative of $\mathrm{R}_{\mathrm{s}}$ during the Snowmelt period, when vegetation was not productive. However, it was most likely that the warming period in Snowmelt promoted degassing from melted ice lenses in the snowpack (Lange et al. 2016), causing "burps" in $R_{\text {eco }}$ over time. Therefore, $R_{s}$ likely continued over the winter months at Bonsai, possibly making it a small annual net source of $\mathrm{CO}_{2}$; however, an annual multi-year investigation will be required to quantify its average yearly net $\mathrm{C}$ contributions and confirm or refute this hypothesis.

The measurement period began with "pulses" of carbon emission during Snowmelt because of degassing air pores in surface ice lenses that melted during rainfall and warm temperatures (Lange et al. 2016). Because of a lengthy melt process from shading (Hrach et al. 2021), theGreen Up period lasted longer at our study site compared to those in other alpine ecosystems. Green Up represented the increase in net seasonal $\mathrm{CO}_{2}$ flux, which led to peak production (maximum GPP and $\mathrm{R}_{\text {eco }}$ ) during the Peak Growing Season. The 2018 Green $U p$ at Bonsai lasted from 24 June to 20 July, ending several weeks later than Green Up at similar ecosystems reported in literature (Kato et al. 2003; Zhao et al. 2010; Knowles et al. 2015), which began Green Up in June and ended by early July. Despite these subalpine wetlands being located at lower latitude (35-40N) compared to Bonsai $(\sim 50 \mathrm{~N})$ and experiencing fewer daylight hours due to less solar input in June and July, they greened up faster in comparison. Our results suggest that the microclimate resulting from horizon shade, extended the Green Upand shortened the Peak Growing Season periods at our site by approximately two weeks.

We found that in general, during the period of increasing shade, the $\mathrm{C}$ flux had a statistically significant relationship with horizon shade. During the period of Dynamic Shade, GPP and $\mathrm{R}_{\text {eco }}$ had a statistically significant negative relationship with shade, while NEE had a statistically significant positive relationship with shade. Each hourly increase in shade per day during Dynamic Shade, decreased GPP by $15 \%$ and increased NEE by $18 \%\left(\mathrm{p}<0.001, \mathrm{R}^{2}=0.65\right)$, indicating that shade negatively impacted $\mathrm{C}$ uptake at our subalpine wetland. Our finding found agreement with Cao et al. (2017), which concluded that NEE has a statistically significant negative linear relationship with $\mathrm{Rg}\left(\mathrm{p}<0.05, \mathrm{R}^{2}=0.27\right)$. However, what we also found is that shade potentially increases or mitigates the overall reduction in available $\mathrm{Rg}$ at our site, by allowing plants to utilize more diffuse radiation during shaded periods (similar to cloudy conditions), thus increasing the overall photosynthetic rate of the ecosystem which would not be observed in direct light. However, further research on this topic is required at our study site.

Beyond shade and Rg, the literature has identified that other environmental variables like VMC (Kato et al. 2003), $\mathrm{T}_{\mathrm{s}}$ (Kato et al. 2003; Zhao et al. 2010; Cao et al. 2017), and $\mathrm{T}_{\mathrm{a}}$ (Zhao et al. 2010; Cao et al. 2017) play a strong role in regulating the $\mathrm{C}$ flux. Past studies in mountain meadow (Knowles et al. 2015), wetland (Millar et al. 2017), and forest ecosystems (Monson et al. 2002) identified temperature and moisture as key controls of seasonal patterns in NEE. Our wetland was a net source in Snow Melt and early Green $U p$, but a sink at the end of Green Up and throughout Peak Growing Season. NEE increased alongside $\mathrm{T}_{\mathrm{s}}$ through Green Up and Peak Growing Season, and quickly responded to an abnormal spike in $\mathrm{T}_{\mathrm{a}}$ and $\mathrm{T}_{\mathrm{s}}$ on September $7^{\text {th }}$ in Late Growing Season. However, GPP at our site during Peak Growing Season was not related to any environmental variable, other than Rg.

WUE of a Subalpine Wetland Exposed to Horizon Shade

Water use efficiency at our site varied in response to changes in plant productivity and water availability throughout the study period. Over the course of the study, average WUE was comparable to a mountain 
meadow at 3,293 m.a.s.l. (Zhu et al. 2014) and wetland at 3,160 m.a.s.l. (Hu et al. 2008) literature. Maximum WUE at our site $\left(5.3 \mathrm{gC}\left(\mathrm{kg} \mathrm{H}_{2} \mathrm{O}\right)^{-1}\right)$ occurred on August $20^{\text {th }}$ and was an order of magnitude greater and occurred several weeks later in the season than the max WUE $\left(2.84 \mathrm{gC}\left(\mathrm{kg} \mathrm{H}_{2} \mathrm{O}\right)^{-1}\right)$ reported by $\mathrm{Hu}$ et al. (2008) on DoY 200 (July $19^{\text {th }}$ ) in their study of an alpine wetland. Although each site was at a greater elevation, Hu et al. (2008) had a similar temperature (annual $-2{ }^{\circ} \mathrm{C}$, July $10{ }^{\circ} \mathrm{C}$ ), precipitation (annual 580 $\mathrm{mm}$ ), and canopy height $(40 \mathrm{~cm})$. Zhu et al temperature (annual $-1.7^{\circ} \mathrm{C}$ ), precipitation (annual $570 \mathrm{~mm}$ ), canopy height $(60-70 \mathrm{~cm}), \mathrm{VMC}(0.3 \%$ in June with steady decline to August). The minimum WUE at our study site $\left(1.4 \mathrm{gC}\left(\mathrm{kg} \mathrm{H}_{2} \mathrm{O}\right)^{-1}\right)$ occurred from June $24^{\text {th }}$ to June 30 th, a similar timeframe (June $17^{\text {th }}$ to June $\left.30^{\text {th }}\right)$ but different magnitude and value $\left({ }^{\sim} 1.5 \mu \mathrm{mol} \mathrm{mol}{ }^{-1}\right)$ as the subalpine forest WUE reported in Monson et al. (2010). From Green up to Late GrowingSeason Bonsai showed a greater WUE as the season progressed, despite decreasing soil moisture, suggesting that shaded subalpine wetlands remain productive through short growing seasons. Recent studies found that during the growing season, WUE increased linearly with lower $\mathrm{Rg}$ and that fluctuations in light availability increased plant productivity (Gao et al. 2018; Kromdijk et al. 2016). Our findings agreed with the literature, that decreased Rg led to a higher WUE (Niu et al. 2011; Han et al. 2013; Gao et al. 2018), but unlike those studies we found that ET and Rg have a non-linear relationship and that diffuse radiation produced by shade can enhance GPP, adding to the reduction in WUE with decreased Rg. Reflecting on our hypothesis, we conclude that WUE was affected by shade at our study site, because shade reduced ET and increased GPP. We hypothesized that GPP might remain the same or be reduced by shade, but we found evidence to suggest shade may actually increase GPP. It cannot be definitively concluded that shade helped increase GPP, since this was not the focus of this study. However, past studies showed that plants are more efficient at photosynthesizing in diffuse radiation (such as during cloudy conditions) as opposed to direct radiation (Gu et al., 2002). Thus, shade did potentially contribute to increased GPP during Dynamic shade at our site, but more detailed studies should be conducted to assess the direct contribution of diffuse radiation on photosynthesis and any leaf-area/greenness changes that occur throughout the growing season congruently.

Under future climate uncertainties, water storage will become increasingly important in the subalpine zone, because wetlands supply forests, which are experiencing increased disturbance (Pomeroy Fang, and Ellis, 2012) and decreased winter snow accumulation (Harpold et al. 2015; Pomeroy, Fang, and Rasouli, 2015). As a result, shaded wetlands provide an opportunity to store large volumes of water for late season runoff, while remaining productive within short growing windows. Therefore, shade may delay or negate any rapid change(s) to subalpine wetland water storage and use, which will help balance anticipated water losses from alpine forests. However, further research is required on snow water equivalence at our wetland, to help understand how snowmelt runoff is stored and its contribution to downstream runoff.

\section{Conclusions}

In this study the growing season carbon and water dynamics of a subalpine wetland located in complex terrain was characterized, filling a gap in research on carbon source/sink dynamics in alpine wetlands and in understanding their controlling variables. This work showed that horizon shade, caused by the local complex terrain, had a significant and substantial effect on water and carbon fluxes, reducing ET and potentially enhancing GPP during peak growing season. This resulted in increased WUE at the site during periods of increased shading. In addition to $\mathrm{Rg}$, temporal variability in ET was related to temporal variability in soil temperature and VPD. Shade impacted the curvature and intercept of the nonlinear ET-Rg relationship at our site. In contrast, temporal variability in GPP at our site was dependent largely on Rg only. Complex topography and shading can create a large range in ET for similar mountain wetland types at similar elevations. Reduced evaporative losses from such ecosystems could help support late season runoff in downstream communities, where water supplies are needed.

\section{Acknowledgements}

In the spirit of reconciliation, we acknowledge that this research was conducted on the tradiation territories of the Blackfoot Confederacy (Siksika, Kainai, Piikani), the Tsuut'ina, the Iyâxe Nakoda Nations, the Métis Nation (Region 3), and all people who make their homes in the Treaty 7 Region of Southern Alberta (Calgary 
Foundation, 2019).

We would like to thank our funding partners, Global Water Futures, Alberta Innovates and Natural Science and Engineering Research Council (NSERC) Discovery Grant programs for the financial support on research conducted within this project. We would also like to thank the shareholders of Fortress Mountain Resort and their Management team for site access, logistical support, and wildlife awareness. Special thanks to Chris Chevalier (President), Chris Mueller (Director of Operations), Thomas Heath (Managing Director), and Mel Folden (Maintenance). Thank you to Jessica Williamson, Sheryl Chau, and Lindsey Langs for their assistance in data collection during summer 2018; Eric Kessel for guidance in soil processing; and Brandon Van Huizen for aid with the horizon shade model. Finally, thank you Matt Bolding, Calvin Lei, and Jordan Reynolds from the Rooney Lab (University of Waterloo) for conducting the vegetation survey and sharing raw data, and to Dr. Derek Robinson and Benjamin Meinen (University of Waterloo) for performing drone flights and processing imagery.

\section{Hosted file}

Figure Captions_Final.pdf available at https://authorea.com/users/296014/articles/515927analysis-of-growing-season-carbon-and-water-fluxes-of-a-subalpine-wetland-in-thecanadian-rocky-mountains-implications-of-shade-on-ecosystem-water-use-efficiency

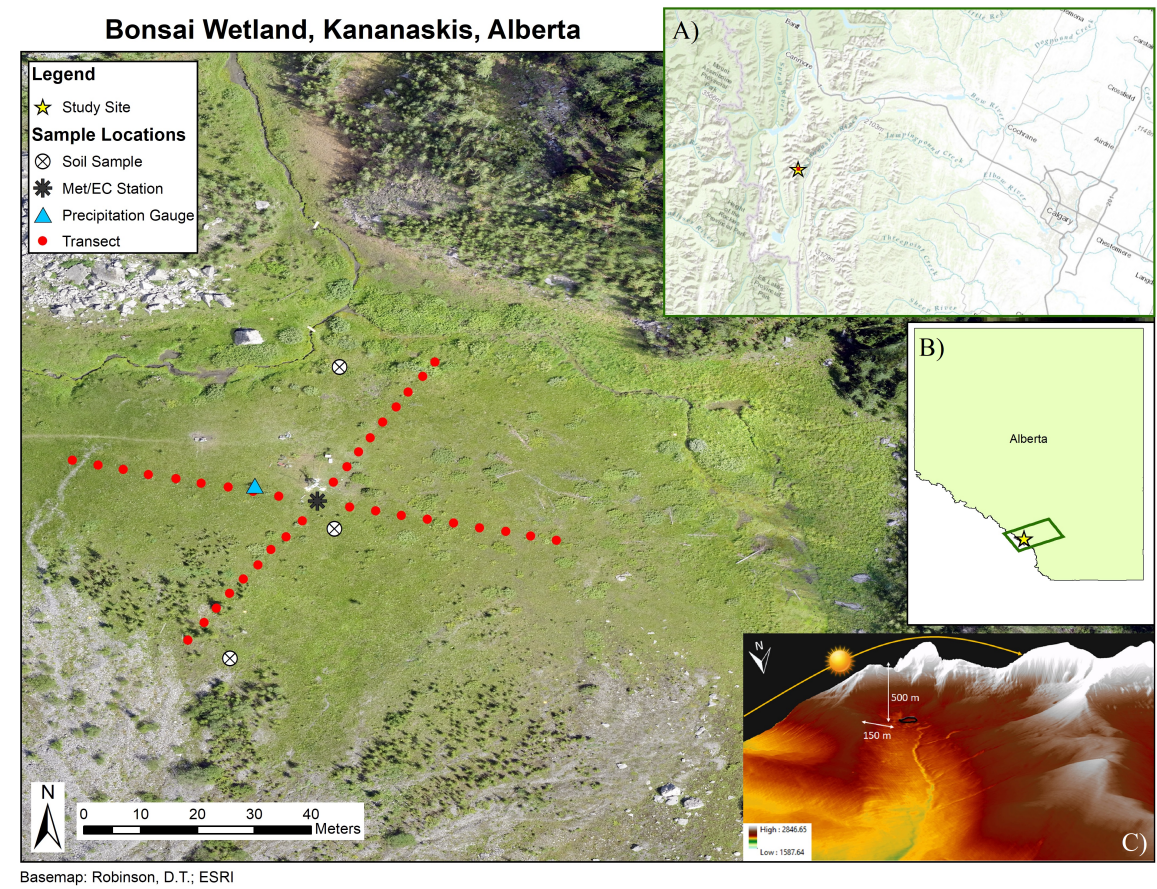



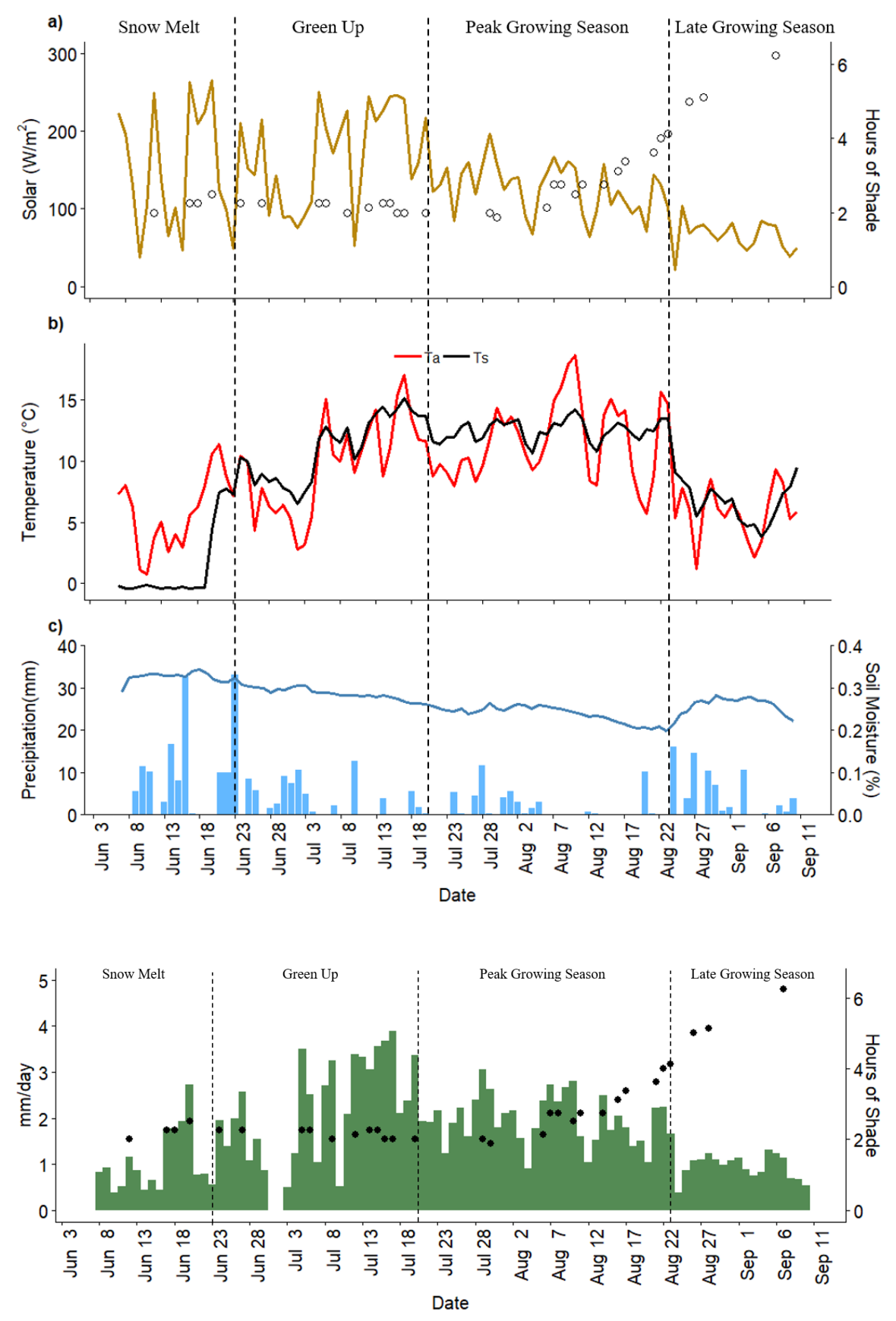
a)
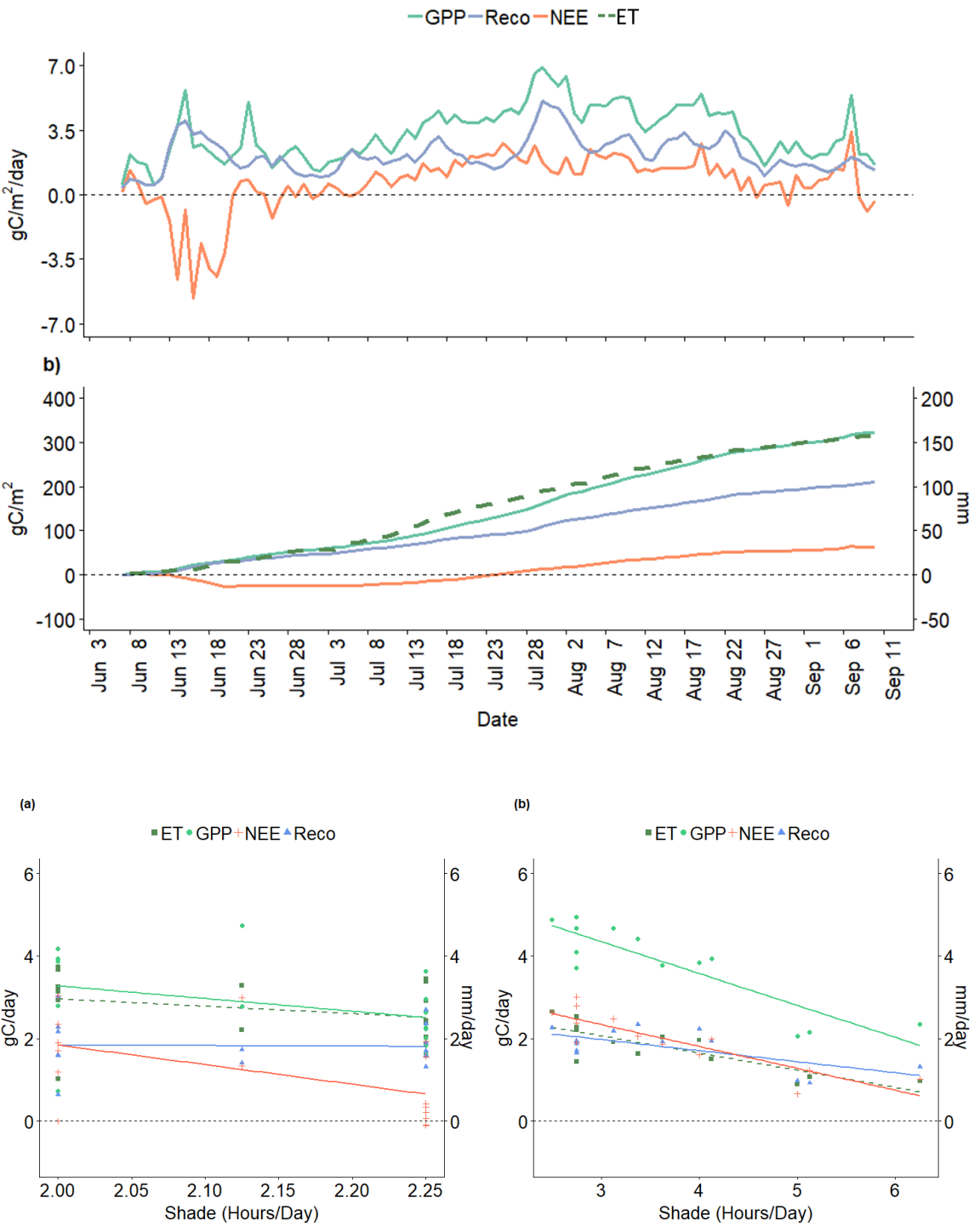

(b)

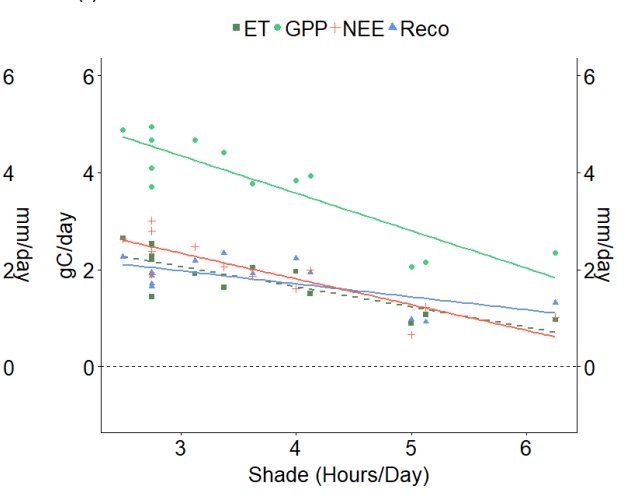



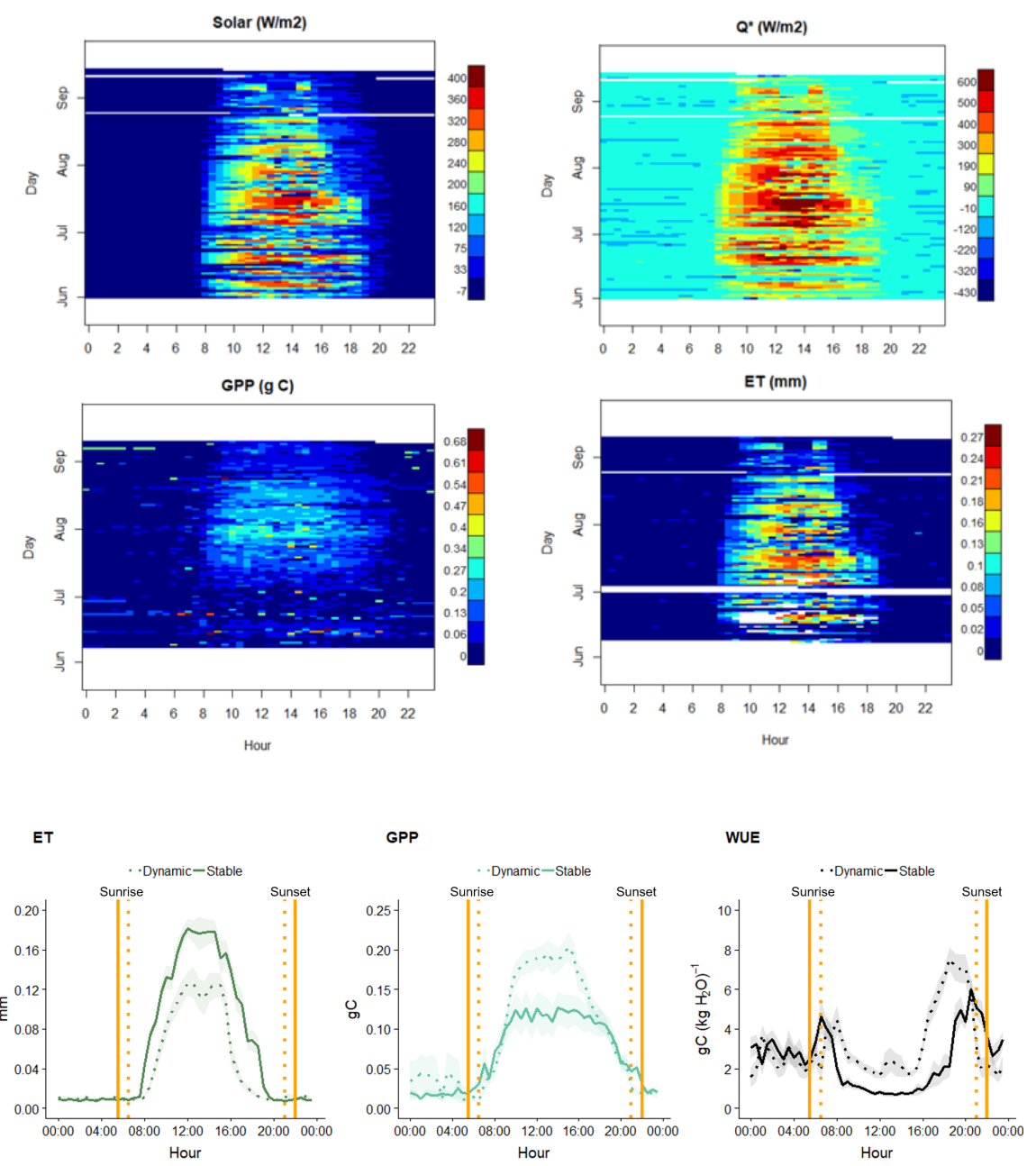

\section{Hosted file}

Table 1.pdf available at https://authorea.com/users/296014/articles/515927-analysis-ofgrowing-season-carbon-and-water-fluxes-of-a-subalpine-wetland-in-the-canadian-rockymountains-implications-of-shade-on-ecosystem-water-use-efficiency

\section{Hosted file}

Table 2.pdf available at https://authorea.com/users/296014/articles/515927-analysis-ofgrowing-season-carbon-and-water-fluxes-of-a-subalpine-wetland-in-the-canadian-rockymountains-implications-of-shade-on-ecosystem-water-use-efficiency

\section{Hosted file}

Table 3.pdf available at https://authorea.com/users/296014/articles/515927-analysis-ofgrowing-season-carbon-and-water-fluxes-of-a-subalpine-wetland-in-the-canadian-rockymountains-implications-of-shade-on-ecosystem-water-use-efficiency

\section{Hosted file}

Table 4.pdf available at https://authorea.com/users/296014/articles/515927-analysis-ofgrowing-season-carbon-and-water-fluxes-of-a-subalpine-wetland-in-the-canadian-rockymountains-implications-of-shade-on-ecosystem-water-use-efficiency 


\section{Hosted file}

Table 5.pdf available at https://authorea.com/users/296014/articles/515927-analysis-ofgrowing-season-carbon-and-water-fluxes-of-a-subalpine-wetland-in-the-canadian-rockymountains-implications-of-shade-on-ecosystem-water-use-efficiency 